\title{
Efficacy and safety of brivaracetam for partial-onset seizures in 3 pooled clinical studies
}

OPEN

Elinor Ben-Menachem,

MD, PhD

Rūta Mameniškiene, MD

Pier Paolo Quarato, MD

Pavel Klein, MB, BChir

Jessica Gamage, PhD

Jimmy Schiemann, MD

Martin E. Johnson, PhD

John Whitesides, PhD

Belinda McDonough,

$\mathrm{MB}, \mathrm{BCh}, \mathrm{BAO}$

Klaus Eckhardt, MD

Correspondence to

Dr. Ben-Menachem:

Elinor.Ben-Menachem@neuro.gu.se

Supplemental data at Neurology.org

\section{ABSTRACT}

Objective: To assess the efficacy, safety, and tolerability of adjunctive brivaracetam (BRV), a selective, high-affinity ligand for SV2A, for treatment of partial-onset (focal) seizures (POS) in adults.

Methods: Data were pooled from patients (aged 16-80 years) with POS uncontrolled by 1 to 2 antiepileptic drugs receiving BRV 50,100, or $200 \mathrm{mg} / \mathrm{d}$ or placebo, without titration, in 3 phase III studies of BRV (NCT00490035, NCT00464269, and NCT01261325, ClinicalTrials.gov, funded by UCB Pharma). The studies had an 8-week baseline and a 12-week treatment period. Patients receiving concomitant levetiracetam were excluded from the efficacy pool.

Results: In the efficacy population ( $n=1,160)$, reduction over placebo ( $95 \%$ confidence interval) in baseline-adjusted POS frequency/28 days was 19.5\% (8.0\%-29.6\%) for $50 \mathrm{mg} / \mathrm{d}(\mathrm{p}=$ $0.0015), 24.4 \%$ (16.8\%-31.2\%) for $100 \mathrm{mg} / \mathrm{d}$ ( $p<0.00001)$, and $24.0 \%(15.3 \%-31.8 \%$ ) for $200 \mathrm{mg} / \mathrm{d}(p<0.00001)$. The $\geq 50 \%$ responder rate was $34.2 \%$ (50 mg/d, $p=0.0015)$, $39.5 \%$ (100 mg/d, $p<0.00001)$, and 37.8\% (200 mg/d, $p=0.00003$ ) vs 20.3\% for placebo $(p<0.01$ ). Across the safety population groups ( $n=1,262), 90.0 \%$ to $93.9 \%$ completed the studies. Treatment-emergent adverse events (TEAEs) were reported by $68.0 \%$ BRV overall ( $\mathrm{n}=$ 803 ) and $62.1 \%$ placebo $(n=459)$. Serious TEAEs were reported by $3.0 \%(B R V)$ and $2.8 \%$ (placebo); 3 patients receiving BRV and one patient receiving placebo died. TEAEs in $\geq 5 \%$ patients taking BRV (vs placebo) were somnolence (15.2\% vs 8.5\%), dizziness (11.2\% vs $7.2 \%)$, headache (9.6\% vs $10.2 \%)$, and fatigue (8.7\% vs 3.7\%).

Conclusions: Adjunctive BRV was effective and generally well tolerated in adults with POS.

Classification of evidence: This analysis provides Class I evidence that adjunctive BRV is effective in reducing POS frequency in adults with epilepsy and uncontrolled seizures. Neurology ${ }^{\circledR} 2016 ; 87: 314-323$

\section{GLOSSARY}

$\mathbf{A E D}=$ antiepileptic drug; $\mathbf{B R V}=$ brivaracetam; $\mathbf{C l}=$ confidence interval; GABA $=\gamma$-aminobutyric acid; $\mathbf{L E V}=$ levetiracetam; POS = partial-onset seizure; SUDEP = sudden unexpected death in epilepsy; SV2A = synaptic vesicle protein 2A; TEAE = treatment-emergent adverse event.

Many antiepileptic drugs (AEDs) target sodium channels, calcium channels, or the $\gamma$-aminobutyric acid (GABA) system. ${ }^{1}$ However, up to $30 \%$ of patients do not achieve seizure control with existing $\mathrm{AEDs},{ }^{2}$ so drugs that interact with alternative targets, such as synaptic vesicle protein 2A (SV2A), are likely to have clinical value. The molecular function of SV2A has not been fully determined, but it is implicated in synaptic vesicle cycling and neurotransmission..$^{3-5}$ There is a strong correlation between SV2A binding and anticonvulsant efficacy in animal models of epilepsy. ${ }^{6,7}$ Levetiracetam (LEV) was the first AED to target SV2A..$^{8-10}$

\footnotetext{
From the Institute for Clinical Neuroscience and Physiology (E.B.-M.), Sahlgrenska Academy, University of Gothenburg, Sweden; Clinic of Neurology and Neurosurgery (R.M.), Medical Faculty, Vilnius University; Neurology Centre (R.M.), Vilnius University Hospital Santariškiụ Klinikos, Vilnius, Lithuania; IRCCS Instituto Neurologico (P.P.Q.), Centro per la Chirurgia dell'Epilessia, Pozzilli, Italy; Mid-Atlantic Epilepsy and Sleep Center (P.K.), Bethesda, MD; QXV Communications (J.G.), Macclesfield, UK; UCB Pharma (J.S., M.E.J., J.W., K.E.), Raleigh, NC; and UCB Pharma (B.M.), Slough, UK.

Go to Neurology.org for full disclosures. Funding information and disclosures deemed relevant by the authors, if any, are provided at the end of the article. The Article Processing charge was paid by UCB Pharma.

This is an open access article distributed under the terms of the Creative Commons Attribution-NonCommercial-NoDerivatives License 4.0 (CC BY-NC-ND), which permits downloading and sharing the work provided it is properly cited. The work cannot be changed in any way or used commercially.
} 
Brivaracetam (BRV) (UCB Pharma, Brussels, Belgium), a newer member of the racetam class, was rationally designed to selectively target SV2A with a high binding affinity, ${ }^{11} 15$ - to 30 -fold greater than that of LEV. ${ }^{12}$ In animal models of focal and generalized epilepsy, BRV shows more potent seizure protection than LEV. ${ }^{12,13}$ At therapeutically relevant concentrations, BRV shows no effect on voltage-gated potassium channels ${ }^{14}$ or sustained repetitive firing in voltage-gated calcium channels, ${ }^{15}$ nor does it bind to AMPA or $\mathrm{GABA}_{\mathrm{A}}$ receptors or transporters. ${ }^{12}$ Therefore, BRV does not appear to act via conventional AED mechanisms.

The BRV clinical development program included 2 phase II and 3 phase III fixeddose studies in patients with epilepsy, primarily those with uncontrolled partial-onset (focal) seizures (POS) (NCT00175929, NCT 00175825, NCT00490035, NCT00464269, NCT01261325; ClinicalTrials.gov). ${ }^{16-20}$ Herein, we present pooled efficacy and safety analyses for the 3 fixed-dose phase III studies: N01252 (NCT00490035), ${ }^{18}$ N01253 (NCT00464269), ${ }^{20}$ and N01358 (NCT01261325). ${ }^{19}$

METHODS BRV phase III program. The design and methodology of the 3 randomized, double-blind, placebo-controlled, fixeddose phase III studies have been published previously ${ }^{18-20}$ (figure 1A). The studies were conducted in Europe, North America, South America, Asia, and Australia from September 2007 to December 2013. The BRV dosages ranged from $5 \mathrm{mg} / \mathrm{d}$ (N01253) to $200 \mathrm{mg} / \mathrm{d}$ (N01358), initiated without up-titration.

Key inclusion and exclusion criteria. Eligible patients were male or female, aged 16 to 70 years with body weight $\geq 45 \mathrm{~kg}$ in studies N01252 and N01253, and 16 to 80 years with body weight $\geq 40 \mathrm{~kg}$ in N01358. All patients had uncontrolled, wellcharacterized POS, with or without secondary generalization, despite treatment with 1 to 2 AEDs (vagal nerve stimulation was counted as an AED in study N01358 only). Patients must have experienced $\geq 8$ POS during the 8 -week baseline period, averaging $\geq 4$ POS per 28 days. For study N01358 only, patients also had $\geq 2$ POS during each 4-week interval of the baseline period (i.e., weeks $0-4,1-5$, etc.).

Concomitant AEDs were kept stable for $\geq 1$ month before study entry and throughout the treatment periods. Concomitant LEV use was restricted to $<20 \%$ of patients in N01252 and N01253. In study N01358, treatment with LEV concomitantly or $\leq 90$ days before entering the study was not permitted.

Standard protocol approvals, registrations, and patient consents. The studies were approved by an appropriate ethical standards committee and conducted in accordance with applicable regulatory requirements, including International Conference on Harmonisation/Good Clinical Practice requirements. The trials were registered on ClinicalTrials.gov (NCT00490035,
NCT00464269, NCT01261325). Written informed consent was obtained from each patient (or their legal guardian) before enrollment.

Pooled analysis. Data from N01252, N01253, and N01358 were pooled by BRV dosage. The 5 and $20 \mathrm{mg} / \mathrm{d}$ dosage groups were excluded because of limited efficacy. The efficacy population comprised all patients from the primary efficacy analyses, randomized to BRV dosages of 50,100 , or $200 \mathrm{mg} / \mathrm{d}$, or placebo, excluding those taking concomitant LEV in studies N01252 and N01253. The safety population comprised all patients randomized to BRV dosages of 50,100, or $200 \mathrm{mg} / \mathrm{d}$, or placebo, who took $\leq 1$ dose of study drug, including those taking concomitant LEV.

Endpoints. The primary endpoints were percent reduction in POS frequency over placebo per 28 days and $\geq 50 \%$ responder rate. Secondary endpoints included percent reduction in POS frequency from baseline to treatment period, seizure freedom during the treatment period, and categorized reduction in POS frequency from baseline to treatment period $(100 \%-75 \%$ reduction, $75 \%-50 \%$ reduction, etc.). Prespecified subgroup analyses by AED inducer status and number of prior AEDs were conducted for percent reduction in POS frequency from baseline.

For consistency with study N01358, treatment-emergent adverse events (TEAEs) for studies N01252 and N01253 were recoded from the Medical Dictionary for Regulatory Activities (MedDRA) version 9.0 to version 15.0. Laboratory parameters, vital signs, body weight, and ECG findings were pooled and summarized.

Classification of evidence. Primary research question: Is adjunctive BRV effective for treating POS in adults with epilepsy and uncontrolled seizures? This analysis provides Class I evidence that adjunctive BRV is effective in reducing POS frequency in adults with epilepsy and uncontrolled seizures. Percent reduction (95\% confidence interval [CI]) over placebo in baseline-adjusted POS frequency per 28 days was $19.5 \%(8.0 \%-29.6 \%)$ for BRV $50 \mathrm{mg} / \mathrm{d}(p=0.001), 24.4 \%(16.8 \%-31.2 \%)$ for BRV $100 \mathrm{mg} / \mathrm{d}(p<0.001)$, and $24.0 \%(15.3 \%-31.8 \%)$ for BRV $200 \mathrm{mg} / \mathrm{d}(p<0.001)$. The $\geq 50 \%$ responder rate was $34.2 \%$, $39.5 \%$, and $37.8 \%$ for BRV $50 \mathrm{mg} / \mathrm{d}(p=0.002), 100 \mathrm{mg} / \mathrm{d}$ $(p<0.001)$, and $200 \mathrm{mg} / \mathrm{d}(p<0.001)$, respectively, compared with $20.3 \%$ for placebo.

Statistical analysis and methodology. Statistical analyses were conducted for descriptive purposes only; no prespecified $\alpha$ level for statistical significance was defined. To allow pooling, percent reduction in POS frequency over placebo data from N01252 and N01253 were adjusted from a 7-day to a 28-day time period. For patients who discontinued, 28-day adjusted seizure frequencies were calculated from the available data.

Pooled percent reduction in POS frequency over placebo per 28 days was assessed by analysis of covariance with logtransformed 28-day adjusted POS frequency over the treatment period as the outcome, with effects for treatment and study, and log-transformed baseline POS frequency as a continuous covariate. Treatment effects were assessed using percent reduction over placebo based on back-transformation of least-squares means obtained for each treatment group from the analysis of covariance model. Pooled $\geq 50 \%$ responder rate was assessed by logistic regression with effects for treatment and study, and logtransformed baseline POS frequency as a continuous covariate.

For percent reduction in POS frequency from baseline, treatment group comparisons were based on the Wilcoxon-MannWhitney test. Seizure freedom rates were compared using the 
Figure 1 Study designs and patient disposition

A

A Randomization

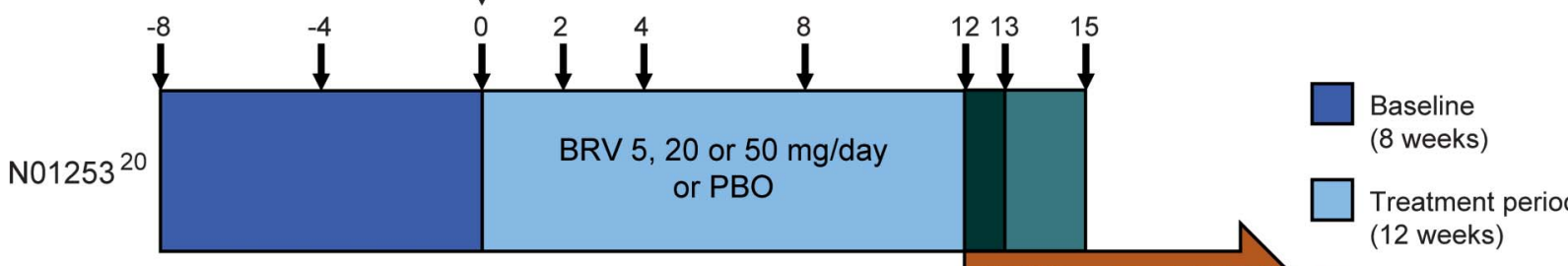

(Sep 2007-Jan 2009; Australia, Brazil, Canada, Mexico and USA) $87.6 \%$ entered LTFU $\square$ Down-titration

(1-4 weeks)
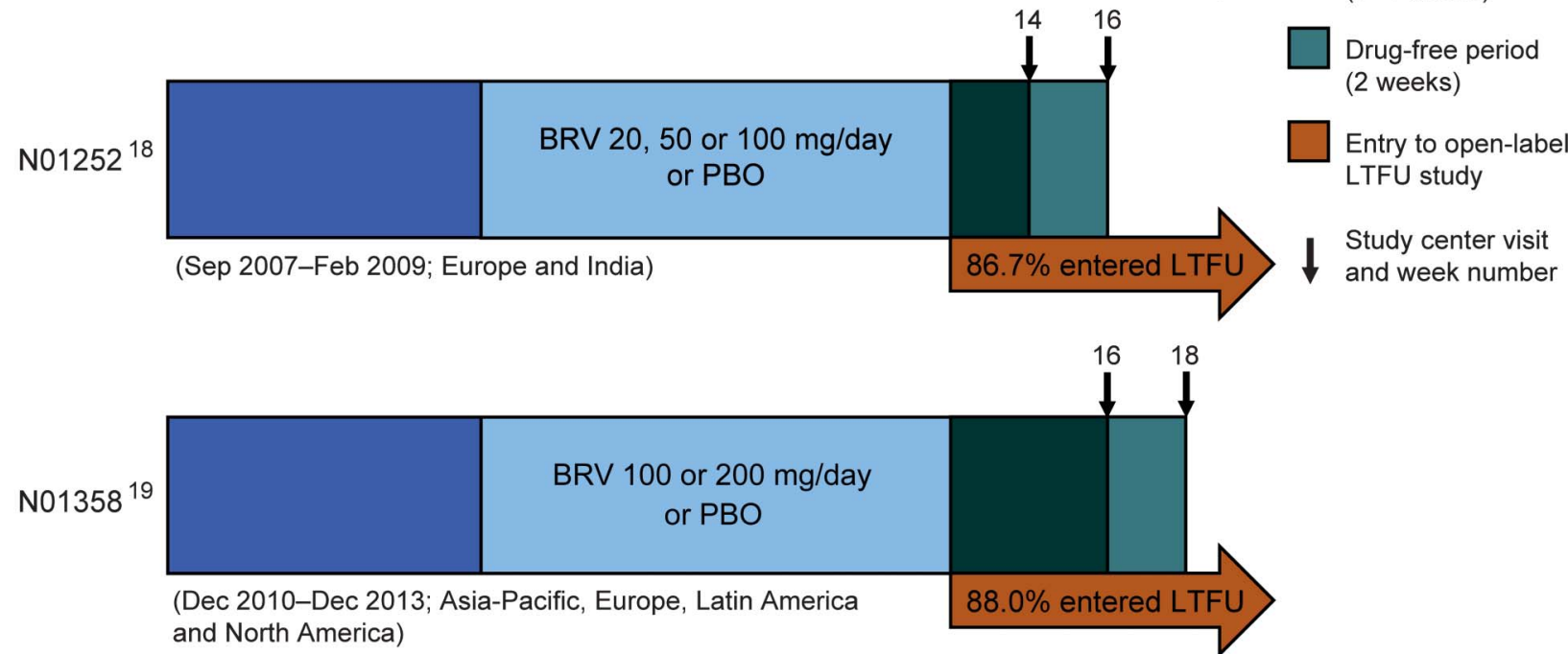

B
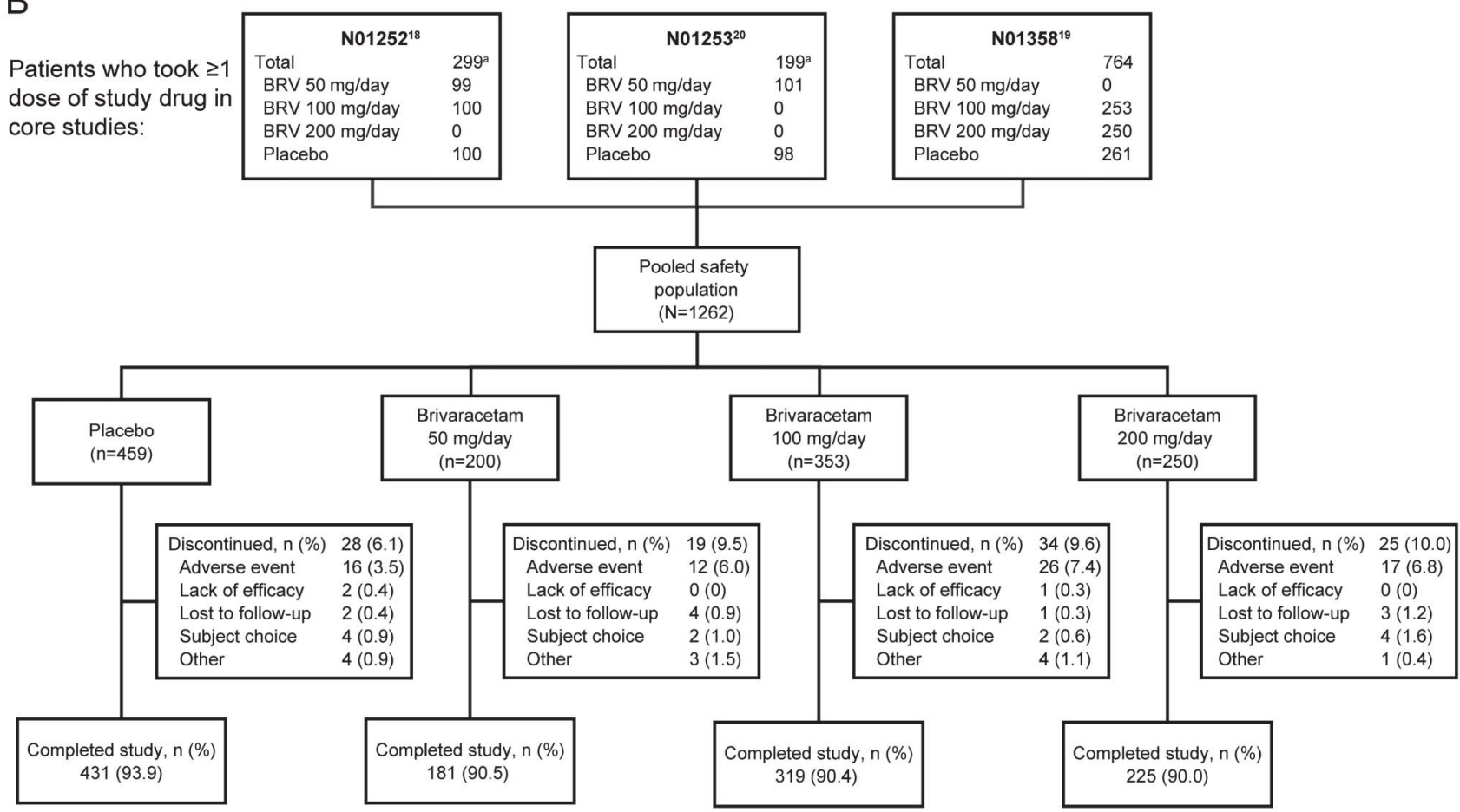

(A) Designs of phase III fixed-dose studies N01253, ${ }^{20}$ N01252, ${ }^{18}$ and N01358.19 Concomitant levetiracetam was limited to $\leq 20 \%$ of patients in studies N01252 and N01253 and was not permitted in study N01358. (B) Patient disposition (safety population). a Patients taking BRV 5 or 20 mg/d were excluded from the pooled analysis. BRV = brivaracetam; LTFU = long-term follow-up; PBO = placebo. 
Fisher exact test. Categorized percent reduction in POS from baseline was assessed using a stratified Mantel-Haenszel test for comparison of row mean scores, stratified by study.

Seizure-free patients completed every seizure diary day for the entire 12-week treatment period without reporting any seizures. For analysis by AED inducer status, carbamazepine, phenobarbital, phenytoin, and primidone were classified as inducers.

RESULTS Patient disposition and demographics. The efficacy population comprised 1,160 patients: 161, 332, and 249 taking BRV 50, 100, and $200 \mathrm{mg} / \mathrm{d}$, respectively, and 418 taking placebo. The safety population comprised 1,262 patients: 276 (21.9\%) from North America, 173 (13.7\%) Latin America, 290 (23.0\%) Eastern Europe, 342 (27.1\%) Western
Europe, and 181 (14.3\%) Asia/Pacific/other. Across treatment groups, $\geq 90.0 \%$ of patients completed the studies (figure 1B).

Most demographic and baseline characteristics for the efficacy population were well-balanced across treatment groups (table 1). Across the studies, the mean duration of epilepsy ranged from 22 to 24 years. Most patients reported complex POS (type IB) during the baseline period, but many patients experienced $\geq 1$ seizure type. LEV status was balanced across treatment groups except for BRV $50 \mathrm{mg} / \mathrm{d}$, which was included only in studies N01252 and N01253. The exclusion of patients taking concomitant LEV in these studies from the pooled analysis

Table 1 Patient demographics and disease characteristics (efficacy population)

\begin{tabular}{|c|c|c|c|c|}
\hline & \multirow[b]{2}{*}{ Placebo $(n=418)$} & \multicolumn{3}{|c|}{ BRV dosage, $\mathrm{mg} / \mathrm{d}$} \\
\hline & & $50(n=161)$ & $100(n=332)$ & $200(n=249)$ \\
\hline Mean age, y (SD) & 37.9 (12.7) & $38.3(13.1)$ & 38.5 (13.3) & $39.7(12.8)$ \\
\hline Female, n (\%) & 207 (49.5) & $79(49.1)$ & $185(55.7)$ & $116(46.6)$ \\
\hline \multicolumn{5}{|l|}{ Racial group, n (\%) } \\
\hline White $^{a}$ & $301(72.0)$ & $120(74.5)$ & $239(72.0)$ & 181 (72.7) \\
\hline Black & $13(3.1)$ & $2(1.2)$ & $8(2.4)$ & $7(2.8)$ \\
\hline Asian & 55 (13.2) & 23 (14.3) & 55 (16.6) & 29 (11.6) \\
\hline Weight, kg, mean (SD) & $75.0(20.0)$ & $71.0(15.2)$ & 73.6 (17.3) & $75.4(19.0)$ \\
\hline $\begin{array}{l}\text { Baseline focal seizure frequency/28 days, } \\
\text { median (Q1-Q3) }\end{array}$ & $9.6(5.5-24.3)$ & $8.9(5.5-17.3)$ & $8.9(5.5-20.6)$ & $9.3(5.5-18.8)$ \\
\hline \multicolumn{5}{|l|}{ Seizure types reported during baseline, ${ }^{b} \mathrm{n}(\%)$} \\
\hline Simple partial (IA) & 167 (40.0) & 47 (29.2) & 119 (35.8) & $98(39.4)$ \\
\hline Complex partial (IB) & $328(78.5)$ & $137(85.1)$ & 273 (82.2) & $215(86.3)$ \\
\hline Partial evolving to secondarily generalized (IC) & $115(27.5)$ & $62(38.5)$ & $100(30.1)$ & 75 (30.1) \\
\hline \multicolumn{5}{|l|}{ No. of prior AEDs, ${ }^{c} n(\%)$} \\
\hline $0-1$ & 100 (23.9) & 56 (34.8) & $81(24.4)$ & $45(18.1)$ \\
\hline $2-4$ & $167(40.0)$ & 79 (49.1) & 114 (34.3) & $84(33.7)$ \\
\hline$\geq 5$ & $151(36.1)$ & $26(16.1)$ & $137(41.3)$ & 120 (48.2) \\
\hline \multicolumn{5}{|l|}{ Most common concomitant AEDs, ${ }^{d} \mathrm{n}(\%)$} \\
\hline Carbamazepine & $172(41.1)$ & $81(50.3)$ & $130(39.2)$ & 93 (37.3) \\
\hline Lamotrigine & 111 (26.6) & $38(23.6)$ & $86(25.9)$ & $61(24.5)$ \\
\hline Valproate & $88(21.1)$ & 44 (27.3) & 86 (25.9) & 48 (19.3) \\
\hline Oxcarbazepine & 57 (13.6) & 21 (13.0) & 56 (16.9) & $50(20.1)$ \\
\hline Topiramate & 83 (19.9) & $10(6.2)$ & 47 (14.2) & 28 (11.2) \\
\hline \multicolumn{5}{|l|}{ LEV status, n (\%) } \\
\hline Prior LEV treatment & $191(45.7)$ & $48(29.8)$ & $158(47.6)$ & $134(53.8)$ \\
\hline LEV-naive & 227 (54.3) & $113(70.2)$ & $174(52.4)$ & 115 (46.2) \\
\hline
\end{tabular}

Abbreviations: AED = antiepileptic drug; BRV = brivaracetam; LEV = levetiracetam; $Q=$ quartile.

a Includes patients described as white, Caucasian, or Hispanic, because of differences in recording racial groups across the 3 studies.

${ }^{b}$ Patients are included in every applicable category for baseline seizure type.

${ }^{c}$ Prior AEDs are those discontinued before study entry. N01252 and N01253 collected AED use within the 5 years before study entry, whereas N01358 collected all history of AEDs used before study entry.

d Used by $\geq 10 \%$ of the overall efficacy population. 
skewed the $50 \mathrm{mg} / \mathrm{d}$ dosage group toward LEV-naive status $(70.2 \%$ of BRV $50 \mathrm{mg} / \mathrm{d}$ patients). All patients took 1 to 2 concomitant AEDs during the treatment period plus study drug (BRV or placebo).

Efficacy. Percent reduction over placebo in baselineadjusted POS frequency per 28 days $(95 \% \mathrm{CI})$ was $19.5 \%(8.0 \%-29.6 \%)$ for BRV $50 \mathrm{mg} / \mathrm{d}(p=0.001)$, $24.4 \%(16.8 \%-31.2 \%)$ for BRV $100 \mathrm{mg} / \mathrm{d}(p<$ $0.001)$, and $24.0 \%(15.3 \%-31.8 \%)$ for BRV $200 \mathrm{mg} / \mathrm{d}(p<0.001)$ (figure $2 \mathrm{~A}$ ). The $\geq 50 \%$ responder rate was $34.2 \%, 39.5 \%$, and $37.8 \%$ for BRV $50 \mathrm{mg} / \mathrm{d}(p=0.002), 100 \mathrm{mg} / \mathrm{d}(p<0.001)$, and $200 \mathrm{mg} / \mathrm{d}(p<0.001)$, respectively, compared

\section{Figure 2 Primary efficacy outcomes}

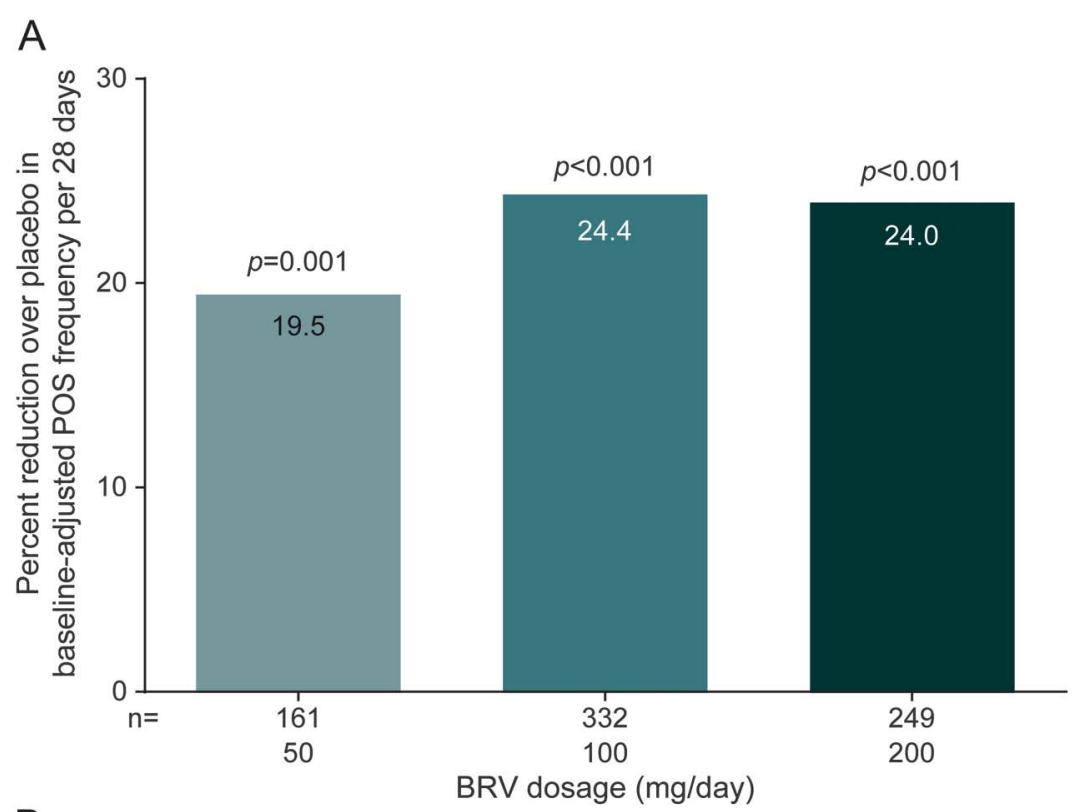

B

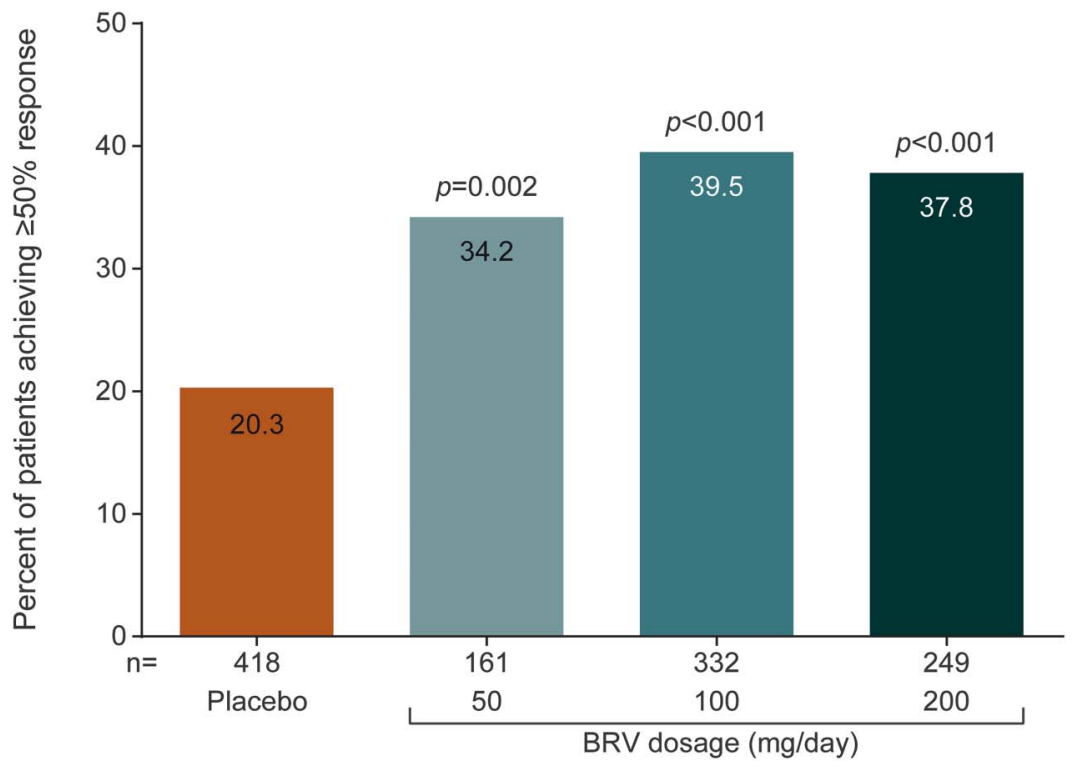

(A) Percent reduction over placebo in baseline-adjusted POS frequency/28 days. (B) $\geq 50 \%$ responder rate. $\mathrm{BRV}=$ brivaracetam; $\mathrm{POS}=$ partial-onset seizure. with $20.3 \%$ for placebo (figure 2B). Odds ratios (95\% CI) vs placebo were 2.15 (1.3-34), 2.56 (1.83.6), and $2.27(1.5-3.3)$ for BRV 50, 100, and $200 \mathrm{mg} / \mathrm{d}$, respectively. Efficacy was greater for BRV 100 and $200 \mathrm{mg} / \mathrm{d}$ than BRV $50 \mathrm{mg} / \mathrm{d}$, with no clear dose response for either outcome.

For the secondary outcomes, median percent reduction in POS frequency from baseline was similar for all BRV dosages and greater than placebo (figure 3A). Median (95\% CI) difference vs placebo was $16.3 \% \quad(8.8 \%-24.0 \%), \quad 18.2 \% \quad(11.5 \%-25.1 \%)$, and $19.2 \%(12.3 \%-26.4 \%)$ for BRV 50, 100, and $200 \mathrm{mg} / \mathrm{d}$, respectively. Seizure freedom rates for all dosages were greater than placebo (figure $3 \mathrm{~B}$ ). The overall seizure freedom rate was $2.5 \%$ (4/161), 5.1\% (17/332), and 4.0\% (10/249) for BRV 50, 100, and $200 \mathrm{mg} / \mathrm{d}$, respectively, compared with $0.5 \%(2 / 418$ patients) for placebo. There was a larger proportion of patients with $50 \%$ to $<75 \%$ and $75 \%$ to $<100 \%$ reduction in POS frequency from baseline for all BRV dosages compared with placebo (figure 3C).

Efficacy subgroup analyses. Patients with more prior AEDs tended to have lower percent reduction in POS frequency from baseline (figure e-1A on the Neurology ${ }^{\circledR}$ Web site at Neurology.org). Percent reduction in POS frequency from baseline was not affected by concomitant AED inducer status (figure e-1B).

Safety and tolerability. In the safety population (1,262 patients), the incidence of TEAEs, severe TEAEs, and serious TEAEs was similar for BRV and placebo (table 2). Patients taking BRV were approximately twice as likely to discontinue because of TEAEs as those taking placebo, with no clear dose effect. The most common serious adverse event in patients taking BRV was a "fall" (3 patients, $0.4 \%$ ); all were related to seizure activity.

Three patients taking BRV and one taking placebo died. The patient taking placebo died of sepsis. Among the BRV-treated patients, an 18-year-old man with history of status epilepticus experienced sudden unexpected death in epilepsy (SUDEP) 1 day after the last confirmed dose of BRV (200 $\mathrm{mg} / \mathrm{d})$. A 34-year-old man experienced a typical POS and was found unresponsive 5 hours later, 9 days after the last confirmed dose of BRV (200 $\mathrm{mg} / \mathrm{d}$ ); a specific cause of death was not recorded. A 21-year-old woman was found unresponsive in her bed 2 weeks after her last confirmed intake of BRV $(50 \mathrm{mg} / \mathrm{d})$; cause of death was recorded as brain hypoxia. All 3 deaths met the criteria for SUDEP. ${ }^{21}$

The most common TEAEs, reported in $\geq 3 \%$ of patients taking BRV, were somnolence, dizziness, headache, and fatigue; the incidence of headache was similar for BRV and placebo $(9.6 \%$ and $10.2 \%$, respectively). Two patients (0.2\%) taking BRV and 

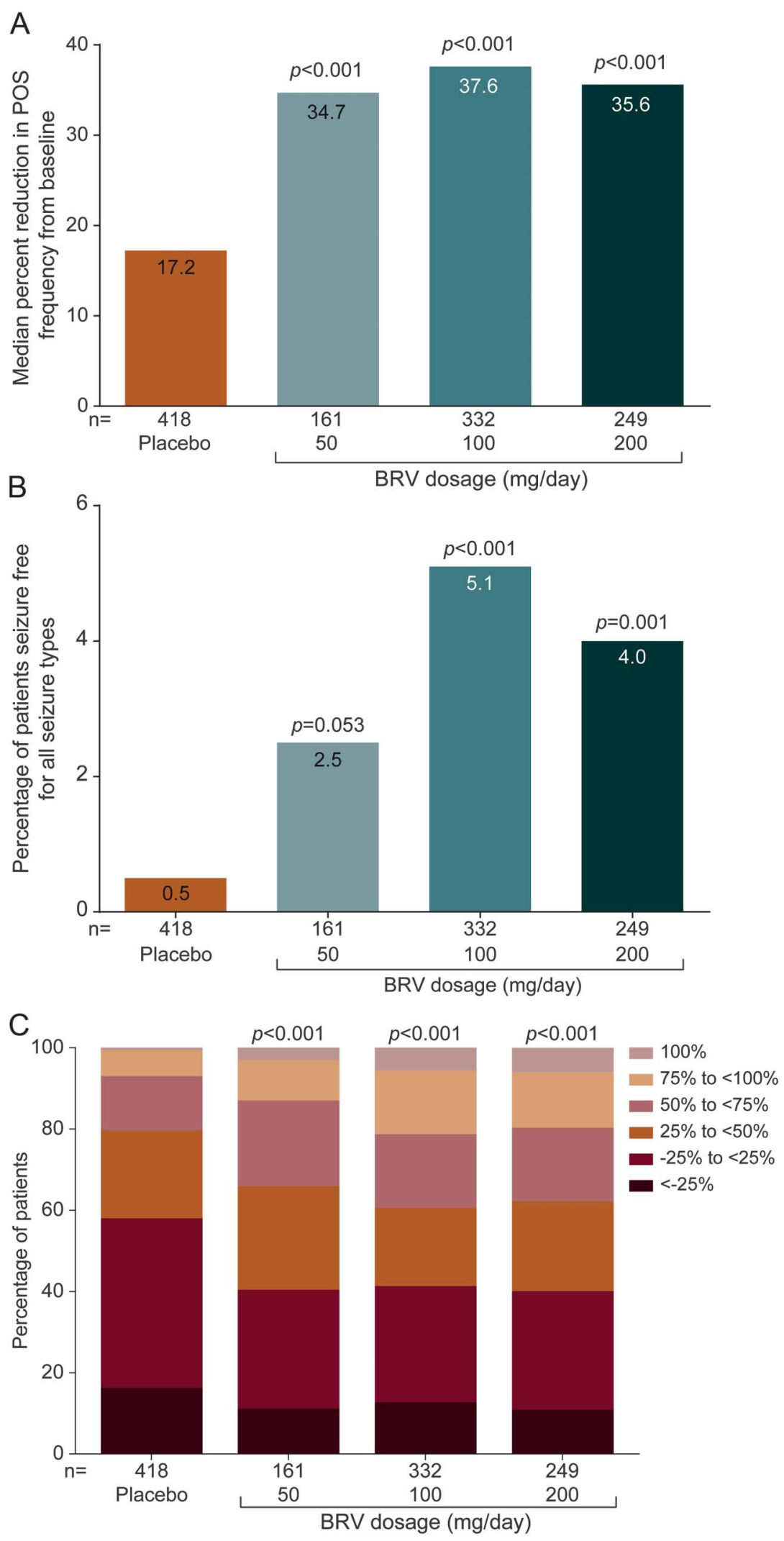

(A) Median percent reduction in POS frequency from baseline. (B) Seizure freedom. (C) Categorized percent reduction in POS frequency per 28 days. $B R V=$ brivaracetam; $P O S=$ partial-onset seizure. 
Table 2 Summary and incidence of TEAEs (reported in $\geq 3 \%$ of patients taking BRV), $n$ (\%) (safety population)

\begin{tabular}{|c|c|c|c|c|c|}
\hline Any TEAE & $285(62.1)$ & $142(71.0)$ & $236(66.9)$ & $168(67.2)$ & $546(68.0)$ \\
\hline Discontinuation because of TEAE & 18 (3.9) & $10(5.0)$ & $27(7.6)$ & $17(6.8)$ & $54(6.7)$ \\
\hline Drug-related TEAEs & 139 (30.3) & $94(47.0)$ & 141 (39.9) & 109 (43.6) & 344 (42.8) \\
\hline Severe TEAEs & $19(4.1)$ & $12(6.0)$ & $17(4.8)$ & $16(6.4)$ & $45(5.6)$ \\
\hline Treatment-emergent SAE & $13(2.8)$ & $6(3.0)$ & 9 (2.5) & 9 (3.6) & $24(3.0)$ \\
\hline Drug-related treatment-emergent SAE & $2(0.4)$ & $1(0.5)$ & $3(0.8)$ & $2(0.8)$ & $6(0.7)$ \\
\hline Deaths & $1(0.2)$ & $1(0.5)$ & 0 & $2(0.8)$ & $3(0.4)$ \\
\hline \multicolumn{6}{|l|}{$\begin{array}{l}\text { TEAEs reported in } \geq 3 \% \text { of } \\
\text { BRV-treated patients overall }\end{array}$} \\
\hline Somnolence & $39(8.5)$ & $23(11.5)$ & 57 (16.1) & $42(16.8)$ & $122(15.2)$ \\
\hline Dizziness & $33(7.2)$ & 23 (11.5) & 31 (8.8) & 36 (14.4) & 90 (11.2) \\
\hline Headache & 47 (10.2) & 32 (16.0) & $26(7.4)$ & $19(7.6)$ & $77(9.6)$ \\
\hline Fatigue & $17(3.7)$ & $14(7.0)$ & $27(7.6)$ & 29 (11.6) & $70(8.7)$ \\
\hline Nausea & $11(2.4)$ & $8(4.0)$ & $15(4.2)$ & 9 (3.6) & $32(4.0)$ \\
\hline Nasopharyngitis & 14 (3.1) & $6(3.0)$ & $12(3.4)$ & 9 (3.6) & 27 (3.4) \\
\hline Irritability & 5 (1.1) & $10(5.0)$ & $9(2.5)$ & $7(2.8)$ & 26 (3.2) \\
\hline
\end{tabular}

Abbreviations: BRV = brivaracetam; SAE = serious adverse event; TEAE = treatment-emergent adverse event. Data represent the number of patients reporting a TEAE at any point during the entire study.

$3(0.7 \%)$ taking placebo reported suicidal ideation. There were no reported suicide attempts or completed suicides.

No clinically meaningful changes from baseline were seen for most hematology parameters. However, there was a small downward trend in neutrophil levels for BRV compared with placebo $(-0.27 \%$ vs $+0.3 \%$ change from baseline for BRV overall and placebo, respectively, expressed as percent of leukocytes). Four patients taking BRV (0.5\%) had neutropenia, compared with none taking placebo. No associated infections were reported and BRV was not discontinued.

There were no clinically meaningful changes from baseline in clinical chemistry, urine analysis parameters, vital signs, or body weight across treatment groups. Overall, the incidence of clinically significant ECG abnormalities was low and comparable with placebo: at baseline, clinically significant ECG abnormalities were found in 5 patients receiving BRV $(0.6 \%)$ and 2 patients receiving placebo $(0.4 \%)$, compared with 8 patients receiving BRV $(1.0 \%)$ and $2 \mathrm{pa}-$ tients receiving placebo $(0.4 \%)$ at the last treatment period assessment. The total number of patients with ECG shifted from normal at baseline to abnormal at last assessment was 54 for BRV (6.8\%) and 33 for placebo (7.3\%).

DISCUSSION This pooled analysis of 3 phase III studies supports the efficacy and safety of adjunctive BRV in a large number of patients with POS.
Since BRV and LEV both exert antiepileptic effects through SV2A, studies N01252 and N01253 limited concomitant LEV to $<20 \%$ of patients. ${ }^{18,20}$ Findings suggested reduced BRV efficacy in patients taking concomitant LEV compared with those with prior LEV exposure or the LEV-naive. Study N01358 excluded patients taking concomitant LEV; however, a post hoc analysis found BRV was effective for both LEV-naive patients and those with prior LEV exposure. ${ }^{19}$ To allow meaningful analysis, the pooled efficacy population also excluded concomitant LEV, thus limiting the overall number of patients available for analysis. However, the pooled safety analysis included all patients who took $\geq 1$ dose of study drug, regardless of LEV status.

In this analysis, the higher BRV dosages (100 and $200 \mathrm{mg} / \mathrm{d}$ ) were more efficacious than BRV $50 \mathrm{mg} / \mathrm{d}$, although there was no clear dose response from 100 to $200 \mathrm{mg} / \mathrm{d}$. Our analysis focused on the proposed therapeutic dosages, but the BRV phase III program explored a wider range. Dose-response results for these studies were variable: BRV 5, 20, and $50 \mathrm{mg} / \mathrm{d}^{16,20}$ showed a dose response, whereas studies using dosages of 50 and $150 \mathrm{mg} / \mathrm{d}^{17}$ and 20,50 , and $100 \mathrm{mg} / \mathrm{d},{ }^{18} \mathrm{did}$ not. These discrepancies are currently unexplained; possibilities include saturation of the SV2A binding site by $B R V$ at dosages $\geq 100 \mathrm{mg} / \mathrm{d}$, a ceiling effect on modulation of the role of SV2A in neurotransmitter release, or other unknown mechanism(s). While the patient groups were generally well-balanced for epilepsy 
duration and number of previous AEDs, it is possible that there were some unidentified, uncontrolled differences in their seizure refractoriness. The lack of dose response is currently being explored further.

The results of this pooled phase III analysis were similar to 2 recent meta-analyses. ${ }^{22,23}$ These included group-level data from studies N01252 and N01253, but not N01358 (the largest study), plus some additional studies and subtherapeutic dosages. Both concluded that BRV has statistically significant efficacy over placebo for POS in adults. For $\geq 50 \%$ responder rate, both found that BRV 20, 50, and $100 \mathrm{mg} / \mathrm{d}$ were effective over placebo, but not $5 \mathrm{mg} / \mathrm{d}$. Tian reported significance over placebo for $150 \mathrm{mg} / \mathrm{d}$, but Ma did not. This dosage was only used in one phase IIb study, ${ }^{17}$ so was not included in our pooled analysis. The significant efficacy for BRV $20 \mathrm{mg} / \mathrm{d}$ in the meta-analyses may be attributable to data from a phase IIb study ${ }^{16}$ that was not included in our pooled analysis.

The efficacy subgroup analyses showed an inverse correlation between number of prior AEDs and reduction in POS frequency. This was expected because seizures in patients with more prior AEDs are generally more difficult to treat, regardless of the AEDs used. ${ }^{24}$ However, the reduction in POS frequency was numerically greater than placebo for all 3 BRV dosages and all subgroups.

Concomitant enzyme-inducing AEDs (carbamazepine, phenobarbital, phenytoin, and primidone) can affect the pharmacokinetics of other medications, ${ }^{25}$ potentially reducing their efficacy. Previous work showed that BRV $400 \mathrm{mg} / \mathrm{d}$ (twice the highest dose in the phase III program) taken concomitantly with carbamazepine $600 \mathrm{mg} / \mathrm{d}$ increases the plasma concentration of carbamazepine epoxide, an active metabolite, 2.3-fold. ${ }^{26}$ Conversely, carbamazepine modestly decreased BRV exposure. ${ }^{26}$ The clinical significance of this interaction on BRV efficacy is under investigation. However, our subgroup analysis showed that BRV efficacy was not affected by concomitant inducers.

No dose-response relationship was identified for the occurrence of adverse events except for somnolence and fatigue. The incidence of psychiatric TEAEs in this pooled analysis of the BRV phase III studies may appear lower than in the corresponding LEV studies. ${ }^{8-10}$ However, direct comparison between these studies is not recommended because of differences in study design and TEAE coding.

Of note, in one of the phase II studies and all phase III studies of BRV, treatment was initiated at the target dose, without up-titration. The possibility of starting a new AED at target dosage is likely to be advantageous in achieving seizure control, as patients receive an effective dosage from the first administration.
There were no reports of suicide attempt or completed suicide during the 3 studies. While 8 BRVtreated patients $(1.0 \%)$ had clinically significant ECG abnormalities, these were not reported as serious drug-related TEAEs. Three deaths were reported in BRV-treated patients, which could be classified as SUDEP per the Ryvlin 2011 criteria, and none in patients taking placebo. However, the incidence of SUDEP reported throughout the BRV program is within the range reported in other AED development programs and community-based epidemiologic studies.

There is currently little information to guide clinical decision-making regarding optimal combination of AEDs based on mechanism of action. ${ }^{27,28}$ However, some studies (clinical and preclinical) and exploratory analyses ${ }^{29,30}$ have shown different outcomes when AEDs of different or similar classes are combined. Although a detailed analysis of response to BRV by LEV status is outside the scope of this report, further analyses are ongoing. The concept of "rational polytherapy" is an area for future prospective studies.

There are several limitations associated with this analysis, including some minor differences in study populations and methodology. The most notable difference was exclusion of patients receiving concomitant LEV from study N01358, ${ }^{19}$ resulting in the pooled efficacy population containing fewer patients than the total phase III population. Because of differences in patient populations, study locations, and methodologies, it is difficult to make comparisons between our data and results of studies with other AEDs: only prospective head-to-head studies can provide such comparisons.

For patients who discontinued during the treatment period, 28-day seizure frequency was calculated based on the available seizure diary data. This might have affected the overall seizure frequency outcome. However, the relatively low discontinuation rate, and lack of dosage-related discontinuation, means that any such effect should be small and equal across dosage groups. Finally, the pooled studies had a relatively short (12-week) double-blind treatment duration. The 3 ongoing open-label, long-term follow-up studies (NCT00175916, NCT00150800, and NCT01339559), in which some patients have received $\mathrm{BRV}$ for $\geq 8$ years, will provide valuable insight into the long-term efficacy profile of BRV.

This pooled analysis of 3 phase III studies supports the efficacy, safety, and tolerability of adjunctive BRV in a large number of adult patients with POS. All 3 dosages of BRV evaluated here $(50,100$, and 200 $\mathrm{mg} / \mathrm{d}$ ) were efficacious, with numerical separation from placebo across multiple endpoints, including seizure freedom. 


\section{AUTHOR CONTRIBUTIONS}

Dr. Ben-Menachem was an investigator in one or more of the contributing studies, critically reviewed the manuscript during its development, and approved the final version of the manuscript. Dr. Mameniškiene was an investigator in one or more of the contributing studies, critically reviewed the manuscript during its development, and approved the final version of the manuscript. Dr. Quarato was an investigator in one or more of the contributing studies, critically reviewed the manuscript during its development, and approved the final version of the manuscript. Dr. Klein was an investigator in one or more of the contributing studies, critically reviewed the manuscript during its development, and approved the final version of the manuscript. Dr. Gamage drafted and revised the manuscript under the direction of the other authors, coordinated the author review process, drafted the response to reviewer comments, and approved the final version of the manuscript. Dr. Schiemann interpreted data, critically reviewed the manuscript during its development, and approved the final version of the manuscript. Dr. Johnson conducted the biostatistical analysis, interpreted data, critically reviewed the manuscript during its development, and approved the final version of the manuscript. Dr. Whitesides interpreted data, critically reviewed the manuscript during its development, and approved the final version of the manuscript. Dr. McDonough interpreted data, critically reviewed the manuscript during its development, and approved the final version of the manuscript. Dr. Eckhardt interpreted data, critically reviewed the manuscript during its development, and approved the final version of the manuscript.

\section{ACKNOWLEDGMENT}

The authors thank the patients and their caregivers, in addition to the investigators and their teams who contributed to the studies. The authors thank Cédric Laloyaux and Anyzeila Diaz (UCB Pharma) for critical review of the manuscript.

\section{STUDY FUNDING}

The studies and the pooled analysis were sponsored by UCB Pharma. UCB Pharma was responsible for the design and conduct of the original phase III studies, and collection, management, and analysis of the data. Medical writing support was provided by QXV Communications (an Ashfield Business, Macclesfield, UK), funded by UCB Pharma. This included drafting the text, coordinating the author review process, and incorporating comments provided by the authors. Additional editorial support provided by QXV Communications included editing and formatting the text; production of original figures; formatting of tables and figures; verifying the accuracy of the data; verifying the accuracy of references; collecting author contribution and conflict of interest statements; and assisting with the online submission process by uploading files. The Article Processing Charge was paid by UCB Pharma.

\section{DISCLOSURE}

E. Ben-Menachem has received research support from UCB Pharma, and has served as a consultant for UCB. R. Mameniškiene and P. Quarato report no disclosures. P. Klein has served on speakers bureaus and advisory boards for Eisai Inc., Sunovion, and UCB Pharma, on advisory boards for Acorda Therapeutics, and has received research support from Acorda Therapeutics, Eisai Inc., Lundbeck, and Marinus Pharmaceuticals Inc. J. Gamage is an employee of QXV Communications; her contribution was funded by UCB Pharma. J. Schiemann was an employee of UCB Pharma when the studies and analyses were conducted. He is a current employee of Teva Pharmaceuticals, Frazer, PA. M. Johnson is an employee of UCB Pharma and holds stock options in UCB Pharma. J. Whitesides is an employee of UCB Pharma. B. McDonough is an employee of UCB Pharma and holds stock options in UCB Pharma. K. Eckhardt is an employee of UCB Pharma. Go to Neurology.org for full disclosures.

Received December 8, 2015. Accepted in final form April 11, 2016.

\section{REFERENCES}

1. Löscher W, Schmidt D. Modern antiepileptic drug development has failed to deliver: ways out of the current dilemma. Epilepsia 2011;52:657-678.

2. Kwan P, Brodie MJ. Early identification of refractory epilepsy. N Engl J Med 2000;342:314-319.

3. Crowder KM, Gunther JM, Jones TA, et al. Abnormal neurotransmission in mice lacking synaptic vesicle protein 2A (SV2A). Proc Natl Acad Sci USA 1999;96:1526815273.

4. Xu T, Bajjalieh SM. SV2 modulates the size of the readily releasable pool of secretory vesicles. Nat Cell Biol 2001;3: 691-698.

5. Mendoza-Torreblanca JG, Vanoye-Carlo A, PhillipsFarfan BV, Carmona-Aparicio L, Gomez-Lira G. Synaptic vesicle protein $2 \mathrm{~A}$ : basic facts and role in synaptic function. Eur J Neurosci 2013;38:3529-3539.

6. Kaminski RM, Matagne A, Leclercq K, et al. SV2A protein is a broad-spectrum anticonvulsant target: functional correlation between protein binding and seizure protection in models of both partial and generalized epilepsy. Neuropharmacology 2008;54:715-720.

7. Kaminski RM, Gillard M, Klitgaard H. Targeting SV2A for discovery of antiepileptic drugs. In: Noebels JL, Avoli M, Rogawski MA, Olsen RW, DelgadoEscuetta AV, editors. Jasper's Basic Mechanisms of the Epilepsies, 4th ed. Bethesda, MD: National Center for Biotechnology Information (US); 2012:1-12.

8. Ben-Menachem E, Falter U. Efficacy and tolerability of levetiracetam $3000 \mathrm{mg} / \mathrm{d}$ in patients with refractory partial seizures: a multicenter, double-blind, responder-selected study evaluating monotherapy. European Levetiracetam Study Group. Epilepsia 2000;41:1276-1283.

9. Cereghino JJ, Biton V, Abou-Khalil B, Dreifuss F, Gauer LJ, Leppik IE. Levetiracetam for partial seizures: results of a double-blind, randomized clinical trial. Neurology 2000;55:236-242.

10. Shorvon SD, Lowenthal A, Janz D, Bielen E, Loiseau P. Multicenter double-blind, randomized, placebo-controlled trial of levetiracetam as add-on therapy in patients with refractory partial seizures. European Levetiracetam Study Group. Epilepsia 2000;41:1179-1186.

11. Kenda BM, Matagne AC, Talaga PE, et al. Discovery of 4-substituted pyrrolidone butanamides as new agents with significant antiepileptic activity. J Med Chem 2004;47: 530-549.

12. Gillard M, Fuks B, Leclercq K, Matagne A. Binding characteristics of brivaracetam, a selective, high affinity SV2A ligand in rat, mouse and human brain: relationship to anticonvulsant properties. Eur J Pharmacol 2011;664:36-44.

13. Matagne A, Margineanu DG, Kenda B, Michel P, Klitgaard H. Anti-convulsive and anti-epileptic properties of brivaracetam (ucb 34714), a high-affinity ligand for the synaptic vesicle protein, SV2A. Br J Pharmacol 2008;154: 1662-1671.

14. Margineanu D, Schlobohm I, Klitgaard H. UCB 34714, a new pyrrolidone anticonvulsant, had no effect on voltage-gated potassium in cultured mouse hippocampal neurons. Epilepsia 2004;45(suppl 3):116.

15. Niespodziany I, Andre VM, Leclere N, Hanon E, Ghisdal P, Wolff C. Brivaracetam differentially affects voltage-gated sodium currents without impairing sustained repetitive firing in neurons. CNS Neurosci Ther 2015;21:241-251. 
16. French JA, Costantini C, Brodsky A, von Rosenstiel P. Adjunctive brivaracetam for refractory partial-onset seizures: a randomized, controlled trial. Neurology 2010;75: 519-525.

17. Van Paesschen W, Hirsch E, Johnson M, Falter U, von Rosenstiel P. Efficacy and tolerability of adjunctive brivaracetam in adults with uncontrolled partial-onset seizures: a phase IIb, randomized, controlled trial. Epilepsia 2013; 54:89-97.

18. Ryvlin P, Werhahn KJ, Blaszczyk B, Johnson ME, Lu S. Adjunctive brivaracetam in adults with uncontrolled focal epilepsy: results from a double-blind, randomized, placebo-controlled trial. Epilepsia 2014;55:47-56.

19. Klein P, Schiemann J, Sperling MR, et al. A randomized, double-blind, placebo-controlled, multicenter, parallelgroup study to evaluate the efficacy and safety of adjunctive brivaracetam in adult patients with uncontrolled partial-onset seizures. Epilepsia 2015;56:1890-1898.

20. Biton V, Berkovic SF, Abou-Khalil B, Sperling MR, Johnson ME, Lu S. Brivaracetam as adjunctive treatment for uncontrolled partial epilepsy in adults: a phase III randomized, double-blind, placebo-controlled trial. Epilepsia 2014;55:57-66.

21. Ryvlin P, Cucherat M, Rheims S. Risk of sudden unexpected death in epilepsy in patients given adjunctive antiepileptic treatment for refractory seizures: a meta-analysis of placebo-controlled randomised trials. Lancet Neurol 2011;10:961-968.
22. Tian X, Yuan M, Zhou Q, Wang X. The efficacy and safety of brivaracetam at different doses for partial-onset epilepsy: a meta-analysis of placebo-controlled studies. Expert Opin Pharmacother 2015;16:1755-1767.

23. Ma J, Huang S, You C. Adjunctive brivaracetam for patients with refractory partial seizures: a meta-analysis of randomized placebo-controlled trials. Epilepsy Res 2015;114:59-65.

24. Schiller Y, Najjar Y. Quantifying the response to antiepileptic drugs: effect of past treatment history. Neurology 2008;70:54-65.

25. Brodie MJ, Mintzer S, Pack AM, Gidal BE, Vecht CJ, Schmidt D. Enzyme induction with antiepileptic drugs: cause for concern? Epilepsia 2013;54:11-27.

26. Stockis A, Chanteux H, Rosa M, Rolan P. Brivaracetam and carbamazepine interaction in healthy subjects and in vitro. Epilepsy Res 2015;113:19-27.

27. Brodie MJ, Sills GJ. Combining antiepileptic drugs: rational polytherapy? Seizure 2011;20:369-375.

28. Ben-Menachem E. Medical management of refractory epilepsy: practical treatment with novel antiepileptic drugs. Epilepsia 2014;55:3-8.

29. Jonker DM, Voskuyl RA, Danhof M. Synergistic combinations of anticonvulsant agents: what is the evidence from animal experiments? Epilepsia 2007;48:412-434.

30. Sake JK, Hebert D, Isojarvi J, et al. A pooled analysis of lacosamide clinical trial data grouped by mechanism of action of concomitant antiepileptic drugs. CNS Drugs 2010;24:1055-1068.

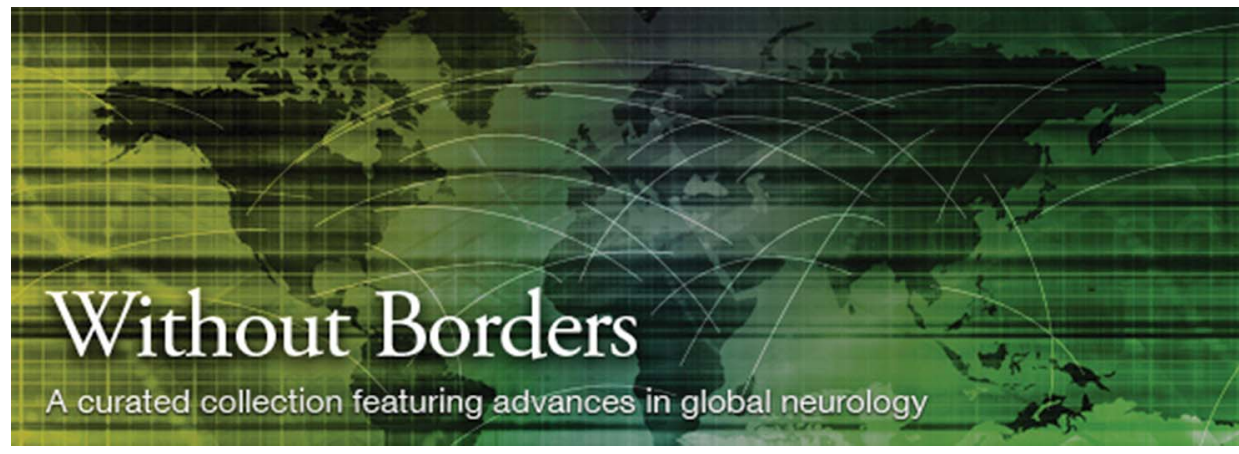

\section{NEW! \\ Without Borders - A curated collection featuring advances in global neurology}

This Neurology ${ }^{\circledR}$ special interest Web site is the go-to source for tracking science and politics of neurology beyond the United States, featuring up-to-the-minute blogs, scholarly perspectives, and academic review of developments and research from Neurology journals and other sources. Curated by Gretchen L. Birbeck, MD, MPH.

Expand your world view at Neurology.org/woborders. 


\section{Neurology}

Efficacy and safety of brivaracetam for partial-onset seizures in $\mathbf{3}$ pooled clinical studies

Elinor Ben-Menachem, Ruta Mameniskiene, Pier Paolo Quarato, et al. Neurology 2016;87;314-323 Published Online before print June 22, 2016

DOI 10.1212/WNL.0000000000002864

This information is current as of June 22, 2016

Updated Information \&
Services
Supplementary Material
References
Citations
Subspecialty Collections

Permissions \& Licensing

Reprints including high resolution figures, can be found at: http://n.neurology.org/content/87/3/314.full

Supplementary material can be found at: http://n.neurology.org/content/suppl/2016/06/22/WNL.0000000000002 864.DC1

This article cites 29 articles, 4 of which you can access for free at: http://n.neurology.org/content/87/3/314.full\#ref-list-1

This article has been cited by 2 HighWire-hosted articles: http://n.neurology.org/content/87/3/314.full\#\#otherarticles

This article, along with others on similar topics, appears in the following collection(s):

All Clinical trials

http://n.neurology.org/cgi/collection/all_clinical_trials

Antiepileptic drugs

http://n.neurology.org/cgi/collection/antiepileptic_drugs

Information about reproducing this article in parts (figures,tables) or in its entirety can be found online at:

http://www.neurology.org/about/about_the_journal\#permissions

Information about ordering reprints can be found online:

http://n.neurology.org/subscribers/advertise

Neurology ${ }^{\circledR}$ is the official journal of the American Academy of Neurology. Published continuously since 1951, it is now a weekly with 48 issues per year. Copyright (O 2016 American Academy of Neurology. All rights reserved. Print ISSN: 0028-3878. Online ISSN: 1526-632X.

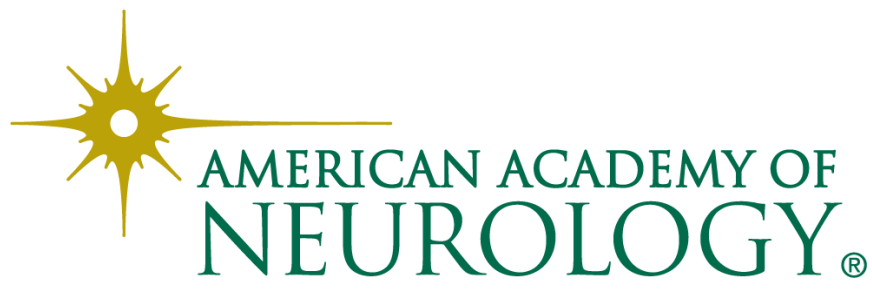

